\title{
Brasil: deuda pública ċquién debe a quién?
}

\author{
Gabriel Strautmann ${ }^{1}$
}

\section{Strautmann, G. (2010) Brasil: Deuda Pública ¿quién debe a quién? Revista Activos, 14, 31-38.}

Recibido: 30 de agosto de 2009 Aprobado: 30 de septiembre de 2009

\section{Resumen}

El documento presenta un análisis sobre la situación de la deuda pública brasilera y argumenta que a pesar de que el gobierno ha anunciado recientemente la condición de Brasil como Acreedor Externo Neto (situación en la que los activos financieros del país son mayores que sus pasivos), esto se debe fundamentalmente a una mala contabilización de los pasivos del país y a la subvaloración de los registros de la deuda pública y privada con el exterior. El autor señala que a pesar de los anuncios positivos del gobierno, el servicio de la deuda externa sigue siendo una carga onerosa para el presupuesto público brasilero, restando valiosos recursos para resolver los grandes problemas sociales y de pobreza que enfrenta el país.

Palabras clave: acreedor externo, pasivos, préstamos intercompañía, derechos sociales, deuda social.

1 Economista del Instituto de Políticas Alternativas para el Cono Sur (PACS), miembro de la Red Brasil sobre Instituciones Financieras Multilaterales y de la Red Jubileo Sur. 
ACTIVOS | REVISTA DE LA FACULTAD DE CONTADURía PÚBLICA

Strautmann, G. (2010). Brazil: Public Debt: Who Owes Whom? Activos Review, 14, 31-38.

\begin{abstract}
The document presents an analysis on the situation of the brazilian public debt and argues that although the government has announced recently the condition of Brazil as clear external creditor (situation in which the financial assets of the country are major than its debits), this owes fundamentally to a bad accounting of the debits of the country and to the underestimation of the records of the public and deprived debt with the exterior. The author points out that in spite of the positive announcements of the government, the service of the external debt keeps on being an onerous load for the Brazilian public budget, reducing valuable resources to solve the big social problems and of poverty that faces the country.
\end{abstract}

Key words: External Creditor, Debits, Loans Intercompany, Social Rights, Social Debt.

Strautmann, G. (2010). Le Brésil: Une Dette Publique: Qui Doit A Qui? Revue Activos, 14, 31-38.

\title{
Résumé
}

Le document présente un analyse sur la situation de la dette publique brésilienne et il argumente que bien que le gouvernement a récemment annoncé la condition du Brésil comme Créancier Externe Net (une situation dans celle que les actifs financiers du pays sont plus grands que ses passifs), cela découle fondamentalement a une mauvaise comptabilisation des passifs du pays et de la sous-évaluation des registres de la dette publique et privée auprès de l'extérieur. L'auteur remarque que malgré les annonces positives du gouvernement, le service de la dette externe continue d'être une charge onéreuse pour le budget public brésilien, en soustrayant des recours précieux pour résoudre les grands problèmes sociaux et de la pauvreté qui affronte le pays.

Mots clé: Créancier externe, des passifs, des prêts inter compagnie, des droits sociaux, une dette sociale. 
El anuncio reciente del ascenso de Brasil a la condición de acreedor externo líquido -situación en la que los activos externos de un país superan sus pasivos- fue recibido con alegría por las autoridades económicas del gobierno brasilero, como un triunfo de nuestra política económica. Según el gobierno, gracias al elevado nivel de nuestras reservas internacionales, tenemos por primera vez recursos suficientes para pagar la deuda externa pública y privada si así lo deseáramos. Esa alegría, sin embargo, se justifica apenas desde una perspectiva estrictamente política, ya que desde el punto de vista económico, la deuda externa es hoy un problema menor, comparado con la deuda interna, y el pago de ambas continúa siendo una barrera para avances sociales urgentes para el país.

Según el Banco Central, en el mes de enero de 2008, Brasil tenía una deuda externa total (pública y privada) de US\$196,200 mil millones de dólares, contra activos que sumarán en el mismo periodo US\$203,193 mil millones de dólares. Esto significa que Brasil tenía en enero una deuda externa negativa de US\$ 6,893 mil millones de dólares, que llevó al país a la condición de acreedor externo líquido.

Los activos externos brasileros están compuestos principalmente por las reservas internacionales del país -que en enero alcanzaron el record de US\$187,534 mil millones de dólares- sin contar con los US\$12,864 mil millones en activos de los bancos comerciales y los US\$2,819 mil millones en créditos al exterior. En relación con los montos de la deuda externa (pasivos), es interesante señalar que desde marzo de 2001 el Banco Central excluye de los cálculos el valor de los de los préstamos intercompañía (deudas de filiales de transnacionales radicadas en Brasil con sus matrices en el exterior). Al sumar el valor de estos préstamos -que entre diciembre de 2003 y febrero de 2008 pasaron de US\$ 20,484 mil millones de dólares a US\$49,926 mil millones de dólares-, el total de la deuda externa brasilera sobrepasa los US $\$ 240$ mil millones de dólares, valor que supera el total de activos, y que desmiente la supuesta condición de acreedor externo líquido.

Pero aún sin considerar los préstamos intercompañía y aceptando la condición de acreedor externo líquido, estamos lejos todavía de considerar la cuestión de la deuda como un problema superado. La prueba de eso es que la estimación del Banco Central para el déficit nominal -resultado final de las cuentas públicas luego del pago del servicio de la deuda- para 2008 es de 1,6 puntos del PIB. Una gran erogación del presupuesto público sigue siendo el pago de los intereses y las amortizaciones de las deudas externa e interna, 
ACTIVOS | REVISTA DE LA FaCULTAD DE CONTADURía PÚBlica

los cuales representan el 30,59\% ${ }^{2}$ del presupuesto general de la Unión ${ }^{3}$ ejecutado en 2007 (Red Brasil, 2008). Para tener una idea de las proporciones, en el mismo año fue gastado apenas el 5,17\% de los recursos del presupuesto en salud, el 2,58\% en educación y el 0,41\% en ciencia y tecnología.

A pesar de que los gastos financieros con el pago de las deudas externa e interna absorben prácticamente una tercera parte del presupuesto federal, como acabamos de señalar, y a pesar de ser estos rubros los que más han crecido a lo largo de estos últimos años, raramente son considerados en los debates sobre la necesidad de aumentar la eficiencia de los gastos públicos. Quien hace esta observación es Ronaldo Coutinho García, del Instituto de Investigación Económica Aplicada (IPEA) ${ }^{4}$, para quien curiosamente el pago de los intereses, comisiones y amotizaciones de las deudas son "intocables, impronunciables, inexistentes para la política fiscal, aunque sean una carga muy pesada” (García,2008,p. 15).

Para García, la estructura actual de los gastos públicos privilegia a un restringido número de familias y de grupos económicos con acceso al mercado financiero, mientras hunde a la mayoría de los brasileros que dependen del desarrollo de políticas públicas redistributivas. De esta manera, el hecho de no reconocer el pago del servicio de la deuda pública equivale a reconocer la "intocabilidad de estos privilegios" (p. 17), cuando lo intocable debería ser la garantía de los derechos sociales e individuales de la mayoría.

La oposición al pago de la deuda externa se convirtió en la bandera de lucha de los partidos de izquierda y de los movimientos sociales latinoamericanos luego del proceso de endeudamiento iniciado por los gobiernos militares de la década de 1970, y la posterior crisis de la deuda en la década de 1980, desencadenada por un alza unilateral de los intereses en los Estados Unidos que arruinó las finanzas de los países endeudados. Durante todo este periodo fue decisiva la actuación de las instituciones financieras multilaterales, como el Banco Mundial y el Fondo Monetario Internacional (FMI). Mientras el primero se encargó de endeudar los países periféricos durante los años 70, ofreciendo crédito fácil para grandes proyectos de infraestructura, muchos de los cuales eran cuestionables, el segundo fue el responsable de la imposición de políticas de mayor liberalización de los mercados en los países endeudados, como condición para el acceso a los préstamos durante las crisis de la década de 1980. El grado de compromiso de estas instituciones con los intereses del

2 Si se consideran los pagos con refinanciamiento (pago de amortizaciones con emisión de más títulos de deuda), el porcentaje aumenta al 53,2\% del presupuesto ejecutado en 2007.

3 Hace referencia al presupuesto federal brasilero (nota del traductor).

4 Por sus siglas en portugués (nota del traductor). 
capital internacional hizo que ellas también se convirtiesen en objetivos de la lucha de los movimientos de izquierda.

De esta manera, al anunciar la nueva condición de Brasil como acreedor externo líquido, sugiriendo con ello que el problema de la deuda está superado, el gobierno de Lula Da Silva pretende una victoria política, repitiendo una estrategia utilizada también en 2005, cuando a través del pago anticipado de US\$ 15,5 mil millones cancelamos nuestra deuda con el FMI. Pero tanto la cancelación de nuestra deuda con el FMI como la supuesta superación de la deuda externa ya no tienen el mismo significado en la actual coyuntura política y económica. El FMI intenta hoy superar una crisis de legitimidad, la cual es urgente luego del evidente fracaso político de las reformas liberales impuestas por la institución a los países a lo largo de la década de $1990^{5}$.

No obstante, la cuestión, como ya lo vimos a través del análisis del déficit público, es que el problema de la deuda está lejos de ser resuelto. La cuestión es que si bien la deuda externa parece un problema menor, poseemos una deuda interna por lo menos tres veces más grande, y es allí donde se encuentra el grueso del problema.

En efecto, la deuda interna alcanzó en febrero de 2008 la astronómica cifra de 1,242 trillones de reales, con lo que supera en casi tres veces el valor de la deuda externa estimada en 417 mil millones de reales ${ }^{6}$. Si consideramos las operaciones de mercado abierto (OMA) del Banco Central, es decir, la colocación de títulos en el mercado para recoger la liquidez generada principalmente por la compra de dólares, la deuda interna sobrepasa los 1,4 trillones de reales (Banco Central do Brasil,2007). De los 237 mil millones de reales ejecutados en el presupuesto federal para el pago de intereses y amortizaciones de la deuda pública brasilera en 2007,219 mil millones fueron para el pago de la deuda interna, frente a los 18 mil millones de la deuda externa, lo que significa una cifra 12 veces superior.

Lo anterior evidencia una expansión meteórica de la deuda interna brasilera, que guarda estrecha relación con la deuda externa que llevó al país a una crisis en la década de 1980, la cual se multiplicó por siete en el espacio de una década. Después de la implantación del Plan Real en 1994, el aumento de las importaciones que siguieron a la inmediata apreciación

5 Es curioso ver cómo a pesar de la cancelación de la deuda con el FMI, la cual nos libera de las condicionalidades impuestas por esta institución, continuamos obedeciendo fielmente las mismas políticas económicas ortodoxas que antes. El mayor ejemplo de ello es el esfuerzo para generar enormes superávit fiscales, de los cuales salen los recursos para el pago de la deuda.

6 Este valor fue convertido en reales con el fin de poder compararlo con la deuda externa. En esta cifra se incluyen los préstamos intercompañía. 
ACTIVOS | REVISTA DE LA FACULTAD DE CONTADURía PÚBLICA

del real provocó un déficit en la balanza comercial del país. Este desequilibrio tuvo que ser compensado con la atracción de capitales especulativos que llegaron al país en busca de ganancias gracias a una de las más elevadas tasas de interés del planeta.

Una de las salidas encontradas por los gestores de la política económica brasilera fue la de transformar la deuda pública -generada a partir del intenso proceso de endeudamiento externo en la décadas anteriores- en títulos negociables en el mercado financiero interno (Fatorelli, 2009). De esta forma, muchos de los acreedores externos se convirtieron en "internos", proceso que se va intensificando entre más se acentúa la tendencia reciente de valorización del real frente al dólar, «En 2007, el Real se valorizó 20\% frente al dólar. Por ende, el inversor extranjero que al inicio del 2007 traía dólares para invertir en títulos de deuda interna brasilera ganó durante el año 13\% en promedio de interés, mas el $20 \%$ cuando convirtió sus ganancias en dólares. Luego en 2007, los extranjeros ganaron una tasa real de interés (en dólares) de más del 30\% en el año».

Entre 1978 y 2007, nuestra deuda externa que era de US\$ 52,8 mil millones pasó a ser de US\$243 mil millones. En ese mismo periodo pagamos US\$ 262 mil millones más de lo que recibimos en préstamo. Por ende, la relación entre la deuda interna actual y la deuda generada durante los años de la dictadura y renegociada sucesivas veces durante el periodo democrático significa que continuamos pagando una deuda ilegítima que ya fue pagada.

Si consideramos además el pasivo ambiental incalculable provocado por los grandes proyectos financiados con recursos de la deuda, llegaremos a la conclusión de que en verdad somos nosotros los verdaderos acreedores de esa deuda. Deberíamos, por tanto, hacer cumplir la Constitución Federal de 1988, que en su artículo 26, en la sección de las disposiciones transitorias, determina la realización de una auditoría de la deuda externa, la cual abriría una oportunidad para retomar el debate sobre el peso del pago de los intereses de la deuda sobre el presupuesto. Y exactamente es lo que está haciendo el gobierno del Ecuador, liderado por el presidente Rafael Correa, que en 2007 creó una Comisión para la Auditoría Integral de Crédito Público (CAIC) bajo la responsabilidad del Ministerio de Economía y Finanzas de ese país, con el objetivo de examinar y avalar el proceso de endeudamiento entre los años de 1976 y 2006 (Red Brasil, 2006).

El trabajo avanza no sólo para que sean evidenciados los impactos económicos y financieros, sino también para mostrar los impactos ambientales derivados del proceso de endeudamiento. Esto significa que la auditoría buscará identificar tanto las tasas de interés, comisiones y multas impuestas, muchas veces de manera unilateral en los contratos de 
crédito - violando la soberanía de los países tomadores-, como también las consecuencias de las condicionalidades asumidas en los contratos de préstamo sobre las condiciones de vida de la población. De esta manera, será analizada la relación entre la finalidad de un proyecto financiado y los impactos sociales y ecológicos provocados, desde una perspectiva multidisciplinaria y de amplios criterios, que ayude a comprobar y dar visibilidad a la ilegalidad, y a la ilegitimidad de la deuda reclamada.

Observamos con expectativa los avances del proceso ecuatoriano de auditoría, con la esperanza de que podamos tomarlo como ejemplo en un futuro próximo. Esperamos que la fuerza de sus resultados abra el camino para retomar el debate sobre el peso de la deuda para la sociedad brasilera y que podamos en una perspectiva más amplia cambiar la percepción común al comprobar que son los pueblos los verdaderos acreedores de esa deuda.

Se anexan a continuación dos figuras que dan cuenta del peso de la deuda brasilera en comparación con otros rubros presupuestales.

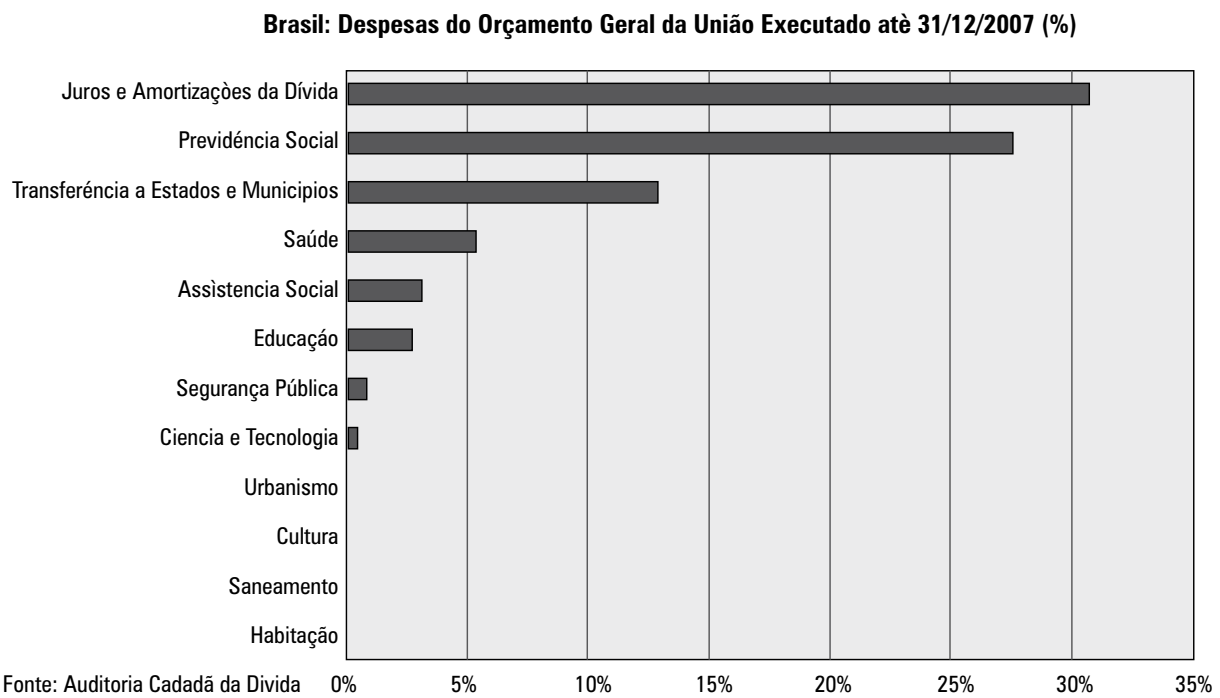

Figura 1. Brasil: Gastos del presupuesto general de la Unión ejecutados hasta el 31/12/2007 (\%) 